\title{
Associations between vocal symptoms and genetic variants in the oxytocin receptor and vasopressin $1 \mathrm{~A}$ receptor gene
}

Sofia Holmqvist Jämsén ${ }^{1}$, Ada Johansson ${ }^{2,1,3}$, Lars Westberg ${ }^{3}$, Pekka Santtila ${ }^{1}$, Bettina von der Pahlen ${ }^{1}$, Susanna Simberg ${ }^{1,4}$

${ }^{1}$ Faculty of Arts, Psychology and Theology, Åbo Akademi University, Turku, Finland

${ }^{2}$ Department of Psychology and Speech-Language Pathology, Faculty of Social Sciences, University of Turku, Turku, Finland

${ }^{3}$ Department of Pharmacology, Institute of Neuroscience and Physiology, Sahlgrenska Academy, University of Gothenburg, Gothenburg Sweden

${ }^{4}$ Department of Special Needs Education, Faculty of Educational Sciences, University of Oslo, Norway

Corresponding author

Sofia Holmqvist Jämsén

Fabriksgatan 2

20500 Åbo

soholmqv@abo.fi

tel. +358408411386

Preliminary results of this research were presented in a poster session at the following meeting:

Pan-European Voice Conference PEVOC 10, 21.8-24.8.2013, Thursday $22^{\text {nd }}$ August 2013, Prague, Check Republic 


\begin{abstract}
Purpose: Oxytocin and arginine vasopressin are associated with different aspects of the stress response. As stress is regarded a risk factor for vocal symptoms, we wanted to explore the association between the oxytocin receptor gene $(O X T R)$ and arginine vasopressin 1A receptor gene (AVPRIA) single nucleotide polymorphisms (SNP) and vocal symptoms. We also wanted to explore whether such effects might be mediated by cortisol since oxytocin and vasopressin associated with cortisol levels.

Method: A population based sample $(N=657)$ of Finnish twins (born 1961-1989) completed a web-questionnaire on the occurrence of vocal symptoms. A total of ( $n=$ 170) participants submitted saliva samples for hormone analysis. A total of 20 OXTR and AVPR1A SNPs were analyzed.
\end{abstract}

Results: Three $O X T R$ polymorphisms (rs2270465, rs2268493, rs7632287) and two AVPR1A polymorphisms (rs1587097, rs1042615) showed nominal effects $(p<.05)$ on vocal symptoms, of which one (rs1587097) remained significant after correcting for multiple testing $(p=.003)$. We found potential mediation of the effect of the OXTR rs2268493 polymorphism on vocal symptoms through levels of cortisol.

Conclusions: The associations between variants of $O X T R$ and $A V P R 1 A$ and vocal symptoms indicate that oxytocin and vasopressin might influence vocal symptoms. The effect of oxytocin seems to be partly mediated through cortisol actions.

Key words: vocal symptoms, stress, oxytocin receptor gene, $O X T R$, arginine vasopressin 1 A receptor, $A V P R 1 A$, cortisol, polymorphism 


\section{Introduction}

Stress has been indicated as a risk factor for vocal symptoms (Dietrich, Verdolini Abott, Gartner-Schmidt \& Rosen, 2008; Giddens, Barron, Byrd-Craven, Clark \& Winter, 2013; Rantala, Hakala, Holmqvist \& Sala, 2012). Variations in fundamental frequency as well as acoustical vocal changes have been reported as vocal symptoms of acute stress (for a review see Giddens et al., 2013). One voice disorder associated with stress is primary muscle tension dysphonia (MTD) (Dietrich et al., 2008; Seifert \& Kollbrunner, 2005). In a study by Dietrich and Verdolini Abbott (2012) results showed that vocal effort increased significantly during stress. The study also showed an increase in infrahyoid muscle activity during perceived stress. Results from a study regarding reactivity to stress in teachers and teacher students showed that individuals with voice problems had a greater reactivity to stress (Gassull, Casanova, Botey \& Amador, 2010). Psychological stress influences many functions in the body, including cardiovascular, immunological and hormonal changes (de Kloet, Joëls \& Holsboer, 2005). Oxytocin (OXT) and arginine vasopressin (AVP) with potent regulators of the stress response (Meyer-Lindenberg, Domes, Kirsch \& Heinrichs, 2011), and OXT can regulate glucocorticoid (GC) levels, for example, cortisol (Heinrichs, Baumgartner, Kirschbaum \& Ehlert, 2003). However, whether the increase of OXT in stressful situations is due to the levels of cortisol, or due to other factors (e.g. social support) is still unclear. The aim of this study was to investigate associations between polymorphisms in the oxytocin receptor $(O X T R)$ and vasopressin $1 \mathrm{~A}(A V P R 1 A)$ genes and vocal symptoms, and whether such associations would be mediated by levels of cortisol.

\section{Cortisol}

Cortisol is a vital hormone associated with physiological and psychological health. The release of cortisol is regulated by the hypothalamo-pituitary-adrenal (HPA) axis, which is influenced by the hormones oxytocin (OXT) and arginine vasopressin (AVP) (MeyerLindenberg et al., 2011). Cortisol is involved in a feedback system in the stress response, including a stress-induced activation of the corticotropin releasing factor (CRF) in the paraventricular nucleus of the hypothalamus resulting in a release of adrenocorticotropic 
hormone (ACTH) from the pituitary, and an ACTH induced release of cortisol from the adrenal cortex (Hellhammer et al., 2009). Psychological stressors increase cortisol levels and previous studies show that stress should be regarded as a risk factor in developing vocal symptoms or dysphonia (Baker, 2008; Chen, Chiang, Chung, Hsiao \& Hsiao, 2010; Dietrich et al., 2008; Dietrich \& Verdolini Abbott, 2012; Gassull et al., 2010; Rantala et al., 2012). In a study by Holmqvist, Johansson, Santtila, Westberg, von der Pahlen and Simberg (submitted) the results showed a positive association between the occurrence of vocal symptoms and the level of salivary cortisol. Salivary cortisol is considered a valid and reliable measure of unbound cortisol in plasma (Vining \& McGinley, 1987).

\section{Oxytocin and arginine vasopressin}

Two nonapeptide hormones associated with stress and levels of cortisol are OXT and AVP. OXT has been associated with antistress patterns (Grewen \& Light, 2011; Heinrichs et al., 2003) and physiological as well as psychological stressors have been associated with increased plasma concentration of OXT (Neumann, Wigger, Torner, Holsboer, \& Landgraf, 2000). Campbell (2008) suggests a feedback system in which stress induces OXT release which in turn attenuates the release of stress hormones, such as cortisol, mediated by the HPA-axis. In a study by Heinrichs et al. (2003), results showed that intranasal OXT reduced endocrine and psychological responses to stress. Participants who received social support as well as a dose of OXT exhibited the lowest cortisol concentrations during stress exposure. Participants who received no social support and placebo instead of OXT demonstrated the highest cortisol response. In a study investigating couple conflicts (Ditzen, Schaer, Gabriel, Bodenmann, Ehlert, \& Heinrichs, 2009) intranasal OXT significantly reduced salivary cortisol levels after a conflict compared with placebo. The results from a meta-analysis (Cardoso, Kingdon, \& Ellenbogen, 2014) showed that OXT did not have a significant effect on the dampening of the cortisol levels during laboratory tasks. However, the results showed an evident effect in tasks that elicited a strong HPA-axis stimulation compared to when the HPA system was minimally activated. As described by Cardoso et al. (2014) oxytocin administration could attenuate cortisol release through inhibition of adrenal activity (Legros, 2001), through modulation of adrenal activity, or by effecting the central 
nervous system by modulation of, for example, amygdala activity (Bethlehem, van Honk, Auyeung, Baron-Cohen, 2013).

Whether the possible OXT increase associated with stress, is due to the stress reaction (cortisol increase) itself (Jezová, D,, Juránková, E., Mosnárová, A., Kriska, M., \& Skultétyová, I. (1996, Tops, van Peer \& Korf, 2007), or result of an actual or a possible social partner (Heinrichs et al., 2003; Selzer, Ziegler \& Pollak, 2010) or cooperative exchange between individuals (Wittig, Crockford, Deschner, Langergraber, Ziegler \& Zuberbühler, 2014) in reaction to a stressful event, is still unclear (Olff et al.,2013).

AVP closely resembles OXT differing only by two amino acids. AVP is one of the key regulators of the HPA axis and enables peripheral cortisol increase (Aguilera \& RabadanDiehl, 2000; Insel, 2010). Whereas OXT might have an indirect effect on cortisol levels and be seen as a stress-reducing hormone, studies indicate that AVP could be seen as the opposite. Based on results from animal experiments (Axelrod \& Reisine, 1984) it has been suggested that AVP increases the hormonal stress response in humans (MeyerLindenberg et al., 2011). This cortisol increase might also be due to other factors such as conflict of interest and aggression (Rosell \& Siever, 2015). The mechanism is still unclear, however, Shalev, Israel, Uzefovsky, Gritsenko, Kaitz and Ebstein (2011) found that intranasal AVP significantly increased the cortisol levels and heart rate in humans during social stress, compared with placebo.

\section{The receptor genes of oxytocin and arginine vasopressin}

Single nucleotide polymorphisms (SNPs) of the OXTR have been associated with various social behaviors one being risk for autism (Jacob, Brune, Carter, Leventhal, Lord \& Cook, 2007; Lerer, Levi, Salomon, Darvasi, Yirmiya, \& Ebstein, 2008; LoParo \& Waldman, 2014). Associations with $O X T R$ has also been found regarding sociobehavioral and emotional domains (Auer, Byrd-Craven, Grant, \& Granger, 2015; Johansson et al., 2012a; Johansson, Westberg, Sandnabba, Jern, Salo \& Santtila, 2012b; LoParo,

Johansson, Walum, Westberg, Santtila, Waldman, 2015; Meyer-Lindenberg et al., 2011; Thompson, Parker, Hallmayer, Waugh \& Gotlib, 2011; Walum et al., 2012; Walum et al., 
2008; Westberg \& Walum, 2015). The influence of $O X T R$ on stress has also been investigated. Rodrigues, Saslow, Garcia, John and Keltner (2009) showed an association between the rs 53576 polymorphism and cardiovascular reactivity across a variety of stressful contexts. Chen, Kumsta, von Dawans, Monakhov, Ebstein, and Heinrichs (2011) found that the same polymorphism was associated with benefit from social support during a psychosocial laboratory stress procedure measuring cortisol response to stress with and without social support. The rs53576 has also been associated with cortisol reactivity and rejection sensitivity (Auer et al., 2015). Myers et al. (2014), in turn, showed that the rs139832701 polymorphism was associated with mood and anxiety symptoms and history of early life stress.

The vasopressin receptor 1A gene polymorphisms (AVPR1A) have in humans been associated with, for example, novelty seeking and harm avoidance (Maher et al., 2011; Meyer-Lindenberg et al., 2009; Walum et al., 2012; Walum et al., 2008; Westberg \& Walum, 2015). In a study by Moons, Way and Taylor (2014) the results showed that polymorphisms in the OXTR and AVPRIA in combination with circulating levels of OXT and AVP, respectively, predicted men's and women's emotional responses to an acute stressor. See Meyer-Lindenberg et al. (2011) and Neumann and Landgraf (2012) for reviews regarding the role and effects of OXT and AVP, as well as their receptor genes. As oxytocin and vasopressin directly or indirectly are associated with the stress response, and stress is an important risk factor for vocal symptoms, we hypothesized that OXTR and AVPRIA polymorphism possibly could influence the occurrence of vocal symptoms. The aim of the current study was to explore the genic and single SNP associations between OXTR and AVPRIA and vocal symptoms. We also hypothesized that the associations between the receptor genes and vocal symptoms might be mediated through cortisol levels, since cortisol levels have shown a positive association with vocal symptoms in a previous study. 


\section{Method}

\section{Participants}

The participants $(N=657$; men $n=219$, women $n=438)$ consisted of a population based sample of Finnish twins born between 1961 and 1989 who submitted saliva samples for hormone analysis $(n=170)$ and for genotyping $(n=657)$ and completed a webquestionnaire. The sample was a subset of the Genetics of Sexuality and Aggression sample, and the data collections were carried out in 2005 and 2006. The procedures regarding the data collection have been more extensively described in previous studies (Johansson et al., 2013; Simberg, Santtila, Soveri, Varjonen, Sala \& Sandnabba, 2009). For estimates of genetic and environmental effects on vocal symptoms using the present sample the reader is kindly referred to Simberg et al. (2009) and Nybacka, Simberg, Santtila, Sala, and Sandnabba (2012).

\section{Instruments}

The participants completed a web-questionnaire including questions regarding the occurrence of six vocal symptoms during the past 12 months. The symptoms were; Voice becomes strained or tired, Voice becomes hoarse or low in pitch, Voice breaks while talking, Difficulty in being heard, Throat clearing or coughing while talking and Sensation of muscle tension or a lump in the throat. The participants reported how often these vocal symptoms occurred by choosing one of the alternatives daily, weekly, less frequent or never (coded from never $=0$ to daily $=3$ ). The same vocal symptoms have been used in several studies (Nybacka, Simberg, Santtila, Sala \& Sandnabba, 2012; Sala, Laine, Simberg, Pentti \& Suonpää, 2001; Simberg, Sala, Tuomainen, Sellman \& Rönnemaa, 2006; Simberg et al., 2009) and they have been validated against examination performed by a laryngologist regarding organic changes on the vocal folds (Sala et al. 2001). 


\section{Genotyping}

Oragene $^{\mathrm{TM}}$ DNA self-collection kits (DNA, Genotek, Inc., Kanata, Ontario, Canada) were used when collecting the saliva samples. The genotyping of SNPs was performed by KBioscience in the UK (www.lgcgenomics.com) using the KASPar chemistry, a competitive allele specific PCR SNP genotyping system performed with FRET quencher cassette oligos.

Thirteen OXTR SNPs (rs75775, rs2270465, rs1488467, rs4564970, rs4686302, rs237897, rs53576, rs2254298, rs2268493, rs237887, rs 1042778, rs7632287, rs11720238) and seven AVPR1A SNPs (rs10877970, rs10877969, rs3021529, rs1042615, rs11174811, rs1587097) were tested. One AVPR1A SNP (rs3759292) was removed from the analysis after discovering that the number of heterozygotes and rare homozygotes was too low; common homozygotes $=403$, heterozygotes $=3$, rare homozygotes $=0$, missing $=251$. The total number of analyzed SNPs was thus 19. These SNPs were chosen based on reported, or suggested, associations between them and different traits in human studies at the same time as trying to maximize the coverage of the OXTR and the AVPRIA genes (see Table 1). The functionality of these polymorphisms is unclear; however, by choosing SNPs with associations to traits or behavioral variables, we attempted to increase the likelihood of these SNPs being functional. Furthermore, recent studies indicate functionality of some of the OXTR SNPs by showing associations between them and plasma levels of OXT (Feldman et al., 2012), or mRNA expression (unpublished data cited in Walter, Montag, Markett, Felten, Voigt, Reuter, 2012).

The distribution of genotypes did not deviate from Hardy-Weinberg equilibrium. For a number of SNPs the frequency of the rare homozygotes was too low to be analyzed separately. These SNPs were therefore grouped with heterozygotes for these SNPs for all remaining analyses (table 1$)$. 
Table 1 . The 19 analyzed oxytocin receptor gene and arginine vasopressin $1 \mathrm{~A}$ receptor gene single nucleotide polymorphisms $\left(N=657^{\mathrm{a}}\right)$.

\begin{tabular}{|c|c|c|c|c|c|c|}
\hline rs number & $\begin{array}{c}\text { SNP/ } \\
\text { nucleotide } \\
\text { combination }\end{array}$ & $\begin{array}{c}\text { Common } \\
\text { homozygotes } \\
(n)\end{array}$ & $\begin{array}{l}\text { Heterozygotes } \\
\qquad(n)\end{array}$ & $\begin{array}{c}\text { Rare } \\
\text { homozygotes } \\
(n)\end{array}$ & Position & Examples of previous studies analyzing effects of the SNPs \\
\hline $\begin{array}{l}\text { OXTR } \\
\text { rs } 75775^{*}\end{array}$ & $\mathrm{G} / \mathrm{T}$ & G: 233 & 147 & 30 & 5 , & Autism (Wang et al., 2009) \\
\hline rs $1488467^{*}$ & $\mathrm{C} / \mathrm{G}$ & G:381 & 28 & 1 & 5 , & Aggressive behaviour (Johansson et al., 2012a; Johansson et al., 2012b) \\
\hline rs $4564970^{*}$ & $\mathrm{C} / \mathrm{G}$ & G: 372 & 36 & 1 & Intron 1 & Aggressive behaviour (Johansson et al., 2012a; Johansson et al., 2012b) \\
\hline rs4686302* & $\mathrm{C} / \mathrm{T}$ & C: 299 & 99 & 9 & Exon 3 & Empathy (Wu et al., 2012), prosociality (Apicella et al., 2010) \\
\hline rs53576 & $\mathrm{A} / \mathrm{G}$ & G: 131 & 211 & 65 & Intron 3 & $\begin{array}{l}\text { Empathy (Rodrigues et al., 2009; Uzefovsky et al., 2015), prosociality, } \\
\text { amygdala activation (Tost et al., 2010), parenting (Bakermans- } \\
\text { Kranenburg \& van Ijendoorn, 2008) }\end{array}$ \\
\hline rs2254298* & $\mathrm{G} / \mathrm{A}$ & G: 354 & 52 & 4 & Intron 3 & $\begin{array}{l}\text { Prosociality (Israel et al., 2009), autism (LoParo \& Waldman, 2014), } \\
\text { amygdala size (Inoue et al., 2010), empathy (Wu, Li \& Su, 2012) }\end{array}$ \\
\hline rs2268493 & $\mathrm{C} / \mathrm{T}$ & $\mathrm{T}: 151$ & 203 & 54 & Intron 3 & $\begin{array}{l}\text { Autism (Campbell et al., 2011), Asperger syndrome (Napoli et al., } \\
\text { 2014), prosociality (Apicella et al., 2010), affective temperament } \\
\text { (Kawamura et al., 2010) }\end{array}$ \\
\hline rs $7632287^{*}$ & $\mathrm{~A} / \mathrm{G}$ & G: 212 & 164 & 32 & 3 & Pair-bonding (Walum et al., 2012), autism (LoParo \& Waldman, 2014) \\
\hline rs11720238* & $\mathrm{G} / \mathrm{T}$ & G: 333 & 69 & 8 & 3 , & Autism (Tansey et al., 2010), pair-bonding (Walum et al., 2012) \\
\hline rs2270465* & $\mathrm{C} / \mathrm{G}$ & G:213 & 158 & 36 & & Autistic traits (Wermter et al., 2009) \\
\hline
\end{tabular}




\begin{tabular}{|c|c|c|c|c|c|c|}
\hline rs number & $\begin{array}{c}\text { SNP/ } \\
\text { nucleotide } \\
\text { combination }\end{array}$ & $\begin{array}{c}\text { Common } \\
\text { homozygotes } \\
(n)\end{array}$ & $\begin{array}{l}\text { Heterozygotes } \\
\text { (n) }\end{array}$ & $\begin{array}{c}\text { Rare } \\
\text { homozygotes } \\
(n)\end{array}$ & Position & Examples of previous studies analyzing effects of the SNPs \\
\hline \multicolumn{7}{|l|}{$A V P R 1 A$} \\
\hline rs $10877970^{*}$ & $\mathrm{C} / \mathrm{T}$ & $\mathrm{T}: 297$ & 103 & 8 & $5^{\prime}$ & $\begin{array}{l}\text { Extra-pair mating (Zietsch et al., 2015), ejaculatory function (Jern et al., } \\
\text { 2012) }\end{array}$ \\
\hline rs10877969* & $\mathrm{C} / \mathrm{T}$ & T: 293 & 98 & 7 & 5 ' & $\begin{array}{l}\text { Autism spectrum disorders (Yang et al., 2010), extra-pair mating } \\
\text { (Zietsch et al., 2015) }\end{array}$ \\
\hline rs3021529* & $\mathrm{A} / \mathrm{G}$ & G: 333 & 69 & 5 & 5' UTR & $\begin{array}{l}\text { Heroin addiction (Levran et al., 2014), extra-pair mating (Zietsch et al., } \\
\text { 2014), ejaculatory function (Jern et al., 2012) }\end{array}$ \\
\hline rs1042615 & $\mathrm{A} / \mathrm{G}$ & G: 142 & 196 & 75 & Exon 1 & $\begin{array}{l}\text { Extra-pair mating (Zietsch et al., 2015), metabolic variables (Enhörning } \\
\text { et al., 2009), interval walking training effects (Masuki et al., 2010) }\end{array}$ \\
\hline rs11174811* & $\mathrm{A} / \mathrm{C}$ & C: 330 & 70 & 5 & 3 ' & $\begin{array}{l}\text { Drug use, spousal satisfaction, gene expression in human brain tissue } \\
\text { (Maher et al. 2011), heroin addiction (Levran et al., 2014) }\end{array}$ \\
\hline rs $1587097 *$ & $\mathrm{~T} / \mathrm{C}$ & C: 362 & 46 & 3 & 3 ' & Drug use (Maher et al., 2011), heroin addiction (Levran et al., 2014) \\
\hline
\end{tabular}

SNP, single nucleotide polymorphism; G, guanine; T, thymine; C, cytosine; A, adenine; UTR, untranslated region.

*The rare homozygotes were grouped together with the heterozygotes for the remaining analyses.

${ }^{\text {a }}$ The $N$ per row may not always add up to $N=657$, since some SNPs were not identified for all individuals. 


\section{Saliary cortisol}

A Salivette ${ }^{\circledR}$ (SARSTEDT AG \& Co., Nümbrecht, Germany) hormone sampling kit was used when collecting the saliva samples. Each participant was advised to provide saliva samples in the morning after waking up, preferably before 9 a.m, in two collection tubes. Participants were asked not to eat, drink, brush their teeth, or take any medication prior to giving the samples. The participants also were advised to follow the manufacturer's instructions and to deposit approximately $2 \mathrm{~mL}$ of saliva into both collection cups. A number of questions were asked, using a questionnaire, related to the time point of giving the samples were. Additionally, participants were advised to return the samples strait away and if this was not possible they were to keep them in - 20 degrees Celsius and return them as soon as possible. The samples were then kept at - 80 degrees Celsius until analyzed. The extraction of cortisol levels (nmol/L) from the saliva samples was carried out at the Sahlgrenska University Hospital, Clinical Chemistry in Gothenburg, Sweden. They used a RIA-method of analysis, with no specific consideration of the intensity of the cortisol awakening response (CAR).

\section{Statistical analysis}

For all statistical analyses, SPSS 21 for Windows was used (SPSS Inc., Chicago, IL, USA). A composite variable was formed by summing the occurrence of the six vocal symptoms (range 0-18 with higher values indicating more vocal symptoms). The scale was interpreted as representing symptoms of voice problems and was labelled vocal symptoms. This was done based on results from a factor analysis in a study by Simberg et al. (2009) including the same six voice variables in an overlapping sample $(N=1728)$. Using principal components as an extraction method the factor analysis showed that the resulting scale was highly reliable (Cronbach's $\alpha=.84$ ). Since a factor analysis is more reliable conducted on a larger research sample we did not conduct a new analysis for the present study, but chose to refer to previous results.

First, we tested genotype effects of the $\operatorname{OXTR}(n=13)$ and $\operatorname{AVPR} 1 A(n=6) \mathrm{SNPs}$, separately, as predictors of the occurrence of vocal symptoms (dependent variable). Gender was included as a covariate. Since observations from members of the same family 
can be clustered due to genetic or environmental influences shared between family members, a method taking into account such potential inter-dependence between subjects was chosen. The Generalized Estimating Equations (GEE) method is an extension to the Generalized Linear Model to data with an unknown correlation structure between the measurements, making it possible to include all siblings and twins from a family in the analyses (Hanley, Negassa, Edwardes, \& Forrester, 2003). The GEE together with the robust variance estimator is fairly robust in yielding consistent and asymptotically normally distributed parameter estimates even in cases in which the working correlation matrix is misspecified (Gardiner, Luo \& Roman, 2009).

It is not possible to directly obtain effect size estimates using the GEE method in SPSS. Therefore, we estimated the approximate magnitude of the size of significant effects of SNPs on vocal symptoms using Cohen's $d$ for mean differences between groups (Cohen, 1992). For this aim, estimated means and standard errors given by the GEE-method were used, by first converting standard errors to standard deviations using the formula $s d=$ $S E \sqrt{ } n$. The sample size is not corrected for interdependency between individuals from the same family, and therefore, the Cohen's $d$ estimate should only be seen as a guiding approximation of the effect size. Multiple testing was corrected for by changing the significance threshold required to keep Type 1 error rate at $5 \%$ to 0.00341 according to the method by Nyholt (2004) using an estimate of effective number of independent variables proposed by $\mathrm{Li}$ and Ji (2005). This method takes into account linkage disequilibrium (LD) between polymorphisms, that is, that all polymorphisms are not independently inherited. Besides testing for associations between the OXTR and AVPRIA SNPs and vocal symptoms separately, we also tested for gene-based effects of the OXTR and the AVPRIA genes, respectively, on the occurrence of vocal symptoms. This was done using the versatile gene-based test for genome-wide association studies (VEGAS) (Liu et al., 2010). The aim of VEGAS is to analyze if a gene shows a higher association than expected by chance while taking into account LD and number of SNPs per gene. VEGAS reads in the $p$-values of the measured SNPs (as obtained from the GEE-analyses explained above) as well as approximates their LD-pattern using HapMap population data. After annotating a position on the gene for each of the SNPs, the software calculates 
a gene-based test-statistic and an empirical $p$-value through simulations. Since two genes were tested for association, a Bonferroni corrected $p$-value of .025 was used to indicate a significant association in the gene-based tests after correcting for multiple tests.

Next, in order to explore whether possible associations between $O X T R$ and/or AVPRIA SNPs on vocal symptoms could partly be explained by these SNPs affecting cortisol levels, which in turn would affect vocal symptoms, the SNPs with nominal effects on vocal symptoms were chosen for further analyses of such mediational effects, also using the GEE-method. The cortisol values (nmol/L) were winsorized to reduce the effect of potentially spurious outliers, by setting outliers to $3 S D$ from the mean. To analyze if the SNP effects could be mediated by cortisol, we used the three first steps in the mediational model described by Kenny and Judd (2014). The steps consist of showing that the independent variable (SNP) is associated with the outcome variable (vocal symptoms) (step 1), that the independent variable is associated with the mediator (cortisol as dependent variable and the SNP as independent variable) (step 2), and that there still is an association between the mediator (cortisol) and the outcome variable when controlling for the effect of the SNP (both SNP and cortisol as independent variables, vocal symptoms as dependent variable) (step 3). Gender was included as a covariant in all analyses, since vocal symptoms are more common among women.

\section{Ethical considerations}

Participation in the study was voluntary and participants could withdraw from the study at any time. No social security number or other identification data was asked and no invasive examinations were made. The research was conducted with the approval of the Ethics Committee of the Department of Psychology at Abo Akademi University and the Ethics Committee of the Abo Akademi University. 


\section{Results}

\section{Descriptive statistics of the phenotype data}

Of the participants $(N=657), 27.1 \%$ reported frequently occurring (i.e., weekly or more often) throat clearing, $14.1 \%$ had sensations of tension or a lump in the throat, $12.9 \%$ reported that their voice become low hoarse or low in pitch, $11.6 \%$ reported that their voice become strained or tired, $11.3 \%$ reported difficulty in being heard and $8.2 \%$ reported that they had voice breaks while talking. The composite variable vocal symptoms showed a mean value of $4.56(S D=3.36)$. The vocal symptoms and their occurrence during the past 12 months are presented in table 2.

Table 2. Vocal symptoms occurring during the 12 past months $(N=657)$.

\begin{tabular}{lcccccccc}
\hline & \multicolumn{1}{c}{ Daily } & \multicolumn{1}{c}{ Weekly } & \multicolumn{2}{c}{$\begin{array}{c}\text { More } \\
\text { seldom }\end{array}$} & \multicolumn{2}{c}{ Never } \\
\cline { 2 - 10 } & $n$ & $\%$ & $n$ & $\%$ & $n$ & $\%$ & $n$ & $\%$ \\
\hline Throat clearing or coughing while talking & 49 & 7.5 & 129 & 19.6 & 331 & 50.4 & 147 & 22.4 \\
Sensation of muscle tension or a lump in the & & & & & & & & \\
throat & 73 & 11.1 & 20 & 3.0 & 280 & 42.6 & 279 & 42.5 \\
Voice becomes hoarse or low in pitch & 18 & 2.7 & 67 & 10.2 & 318 & 48.4 & 252 & 38.4 \\
Voice becomes strained or tired & 11 & 1.7 & 65 & 9.9 & 282 & 42.9 & 297 & 45.2 \\
Difficulty in being heard & 27 & 4.1 & 47 & 7.2 & 253 & 38.5 & 327 & 49.8 \\
Voice breaks while talking & 12 & 1.8 & 42 & 6.4 & 273 & 41.6 & 329 & 50.1 \\
\hline
\end{tabular}

\section{Associations between OXTR and AVPR1A polymorphisms on vocal symptoms}

The effects of the analyzed SNPs on vocal symptoms can be seen in Table 3. As shown, three OXTR polymorphisms (rs2270465, rs2268493, rs7632287) and two AVPR1A polymorphisms (rs1587097, rs1042615) showed nominally significant effects on vocal symptoms. Participants who were carriers of one or two copies of the cytosine (C) allele $(\mathrm{C}: \mathrm{C} / \mathrm{C}: \mathrm{G})$ on the rs2270465, showed more often occurring vocal symptoms $(M=4.86$, $S E=0.26)$ than participants who were homozygous for the guanine $(\mathrm{G})$ allele $(\mathrm{G}: \mathrm{G})(M=$ $4.08, S E=0.21$; Cohen's $d=0.23$ ). Participants homozygous for the cytosine (C) allele $(\mathrm{C}: \mathrm{C})$ on the rs2268493 showed more often occurring vocal symptoms $(M=5.43, S E=$ 0.41) than participants who were heterozygous (C:T) $(M=4.27, S E=0.24$; Cohen's $d=$ 
0.36) or homozygous for the thymine (T) allele (T:T) $(M=4.34, S E=0.27$; Cohen's $d=$ $0.34)$.

Regarding the rs7632287 carriers of one or two copies of the adenine (A) allele (A:A/ A:G), showed more often occurring vocal symptoms $(M=4.93, S E=0.24)$ than homozygous participants for the guanine $(\mathrm{G})$ allele $(\mathrm{G}: \mathrm{G})(M=4.01, S E=0.22$; Cohen's $d=0.28)$. Participants homozygous for the cytosine $(\mathrm{C})$ allele $(\mathrm{C}: \mathrm{C})$ on the rs 1587097 showed more often occurring vocal symptoms $(M=4.60, S E=0.18)$ than participants who were carriers of one or two copies of the thymine (T) allele (T:T/ T:C) $(M=3.31, S E$ $=0.40$; Cohen's $d=0.41)$. Participants homozygous for the adenine $(\mathrm{A})$ allele $(\mathrm{A}: \mathrm{A})$ on the rs1042615 showed more often occurring vocal symptoms $(M=5.35, S E=0.42)$ than participants who were homozygous for the guanine $(\mathrm{G})$ allele $(\mathrm{G}: \mathrm{G})(M=4.36, S E=$ 0.28; Cohen's $d=0.28)$ or heterozygous (A:G) $(M=4.17, S E=0.23$; Cohen's $d=0.34)$.

After the $\alpha$-level was corrected to account for multiple testing $(\alpha=0.00341)$ the effect of one of the AVPR1A, the rs1587097 remained significant ( Wald $\left.\chi^{2}=8.847, p=0.0029\right)$. Figure 1 shows the association between the rs 1587097 polymorphism and the occurrence of self-reported vocal symptoms.

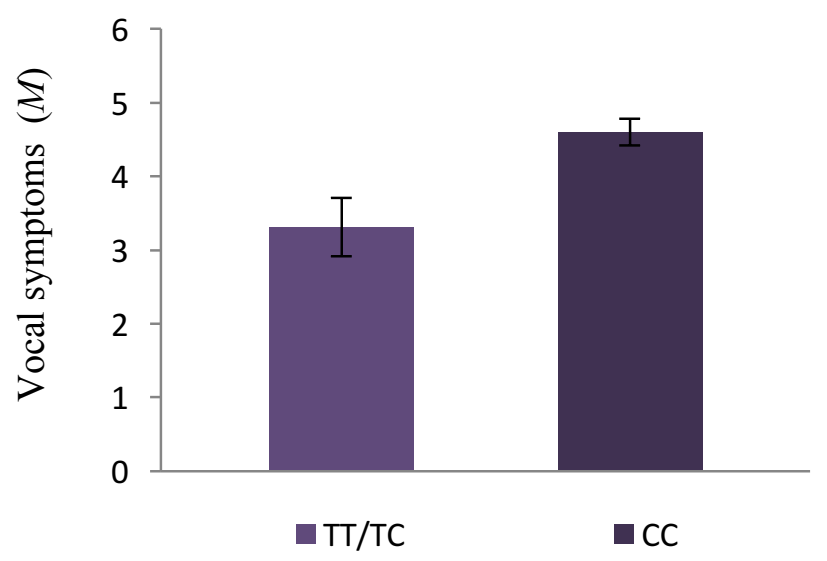

Figure 1. Association between AVPR1A rs1587097 polymorphism and the occurrence of self-reported vocal symptoms during the past 12 months (daily $=3$, weekly $=2$, less frequent $=1$ or never $=0$, composite 
Table 3. The effects of the oxytocin receptor gene SNPs and the arginine vasopressin $1 \mathrm{~A}$ receptor gene SNPs on vocal symptoms (gender included as covariate). Nominally significant effects are marked in bold.

\begin{tabular}{lccc}
\hline SNP & \multicolumn{3}{c}{ Main effect of SNP } \\
\cline { 2 - 4 } & Wald $\chi^{2}$ & $d f$ & $p$ \\
\hline OXTR & 1.975 & 1 & 0.160 \\
rs75775* & 0.666 & 1 & 0.414 \\
rs1488467* & 0.073 & 1 & 0.787 \\
rs4564970* & 0.114 & 1 & 0.736 \\
rs4686302* & 1.476 & 2 & 0.478 \\
rs237897 & 0.066 & 1 & 0.968 \\
rs53576 & 0.651 & 1 & 0.420 \\
rs2254298* & 6.246 & 2 & $\mathbf{0 . 0 4 4}$ \\
rs2268493 & 0.077 & 2 & 0.962 \\
rs237887 & 0.831 & 2 & 0.660 \\
rs1042778 & 7.842 & 1 & $\mathbf{0 . 0 0 5}$ \\
rs7632287* & 1.485 & 1 & 0.223 \\
rs11720238* & 5.412 & 1 & $\mathbf{0 . 0 2 0}$ \\
rs2270465* & & & \\
& & & \\
AVPR1A & & 1 & 0.959 \\
rs10877970* & 0.003 & 1 & 0.904 \\
rs10877969* & 0.014 & 1 & 0.252 \\
rs3021529* & 1.31 & 2 & $\mathbf{0 . 0 4 5}$ \\
rs1042615 & 6.201 & 1 & 0.294 \\
rs11174811* & 1.1 & 1 & $\mathbf{0 . 0 0 3}$ \\
rs1587097* & 8.847 &
\end{tabular}

*The rare homozygotes were grouped together with the heterozygotes.

The gene-based association analysis showed nominal tendencies for effect of the OXTR gene ( $p=.095)$ and the AVPR1A gene ( $p=.079)$ on vocal symptoms. These effects did not, however, pass the gene-based significance threshold corrected for multiple testing (set at $p=.025$ ). 


\section{Cortisol as a possible mediator}

The five polymorphisms with nominally significant effects on vocal symptoms were chosen for further analysis of mediational effects by cortisol. For mediation to occur, these SNPs would have to show effects on cortisol (second criterion for mediation). As shown in Table 4 one OXTR SNP (rs2268493) showed a significant effect on cortisol levels ( Wald $\chi^{2}=8.346, p=0.015$ ), and therefore, only this SNP was analyzed further for possible mediation. Participants homozygous for the cytosine $(\mathrm{C})$ allele $(\mathrm{C}: \mathrm{C})$ on the rs2268493 $(n=11, M=4.31, S E=5.54)$ showed higher cortisol levels than participants who were heterozygous (C:T) $(n=83, M=4.39, S E=5.41)$ or homozygous for the thymine (T) allele (T:T) $(n=66, M=4.18, S E=5.41)$.

Table 4. The association between cortisol and those oxytocin receptor and vasopressin $1 \mathrm{~A}$ receptor gene SNPs showing normally significant effect on vocal symptoms.

\begin{tabular}{lrr}
\hline SNP & Wald $\chi^{2}$ & \\
\hline OXTR & & \\
rs2268493 & 8.346 & 0.015 \\
rs7632287* & 1.631 & 0.202 \\
rs2270465* & 0.00006 & 0.994 \\
AVPR1A & & \\
rs1042615 & 0.206 & 0.902 \\
rs1587097* & 0.032 & 0.858 \\
\hline
\end{tabular}

*The rare homozygotes were grouped together with the heterozygotes.

Note: Gender was included in the analyses as a covariant.

The third criterion for mediation is that cortisol (mediator) needs to be associated with vocal symptoms (outcome). As previously reported by Holmqvist et al. (submitted) using the same sample, cortisol affected the occurrence of vocal symptoms ( Wald $\chi^{2}=10.991, B$ $=0.058, d f=1, p=.001)$. The effect of cortisol on vocal symptoms ( Wald $\chi^{2}=9.658, B=$ $0.055, d f=1, p=.002)$ remained when both cortisol and the rs2268493 SNP were included in the model, indicating mediation. The effect of the SNP (rs2268493) was no longer significant when cortisol was included as a covariate in the model ( Wald $\chi^{2}=$ $0.151, d f=2, p=.927$ ), however, the regression coefficients for $\mathrm{C}: \mathrm{C}$ and $\mathrm{C}: \mathrm{T}$ (genotype 
$\mathrm{T}: \mathrm{T}$ as reference group) were estimated to non-zero (C:C $B=0.123, S E=0.804$ and C:T $B=.209, S E=0.539)$ indicating some remaining variance explained by the SNP.

It should be noted, however, that only 160 individuals had information available both on cortisol levels and the rs2268493 SNP and that the statistical power was reduced as a consequence in comparison to the test of the effect of the SNP without including cortisol in the model $(n=408)$.

\section{Discussion}

Stress is a known risk factor for vocal symptoms. The hormones arginine vasopressin (AVP) and oxytocin (OXT) are both involved in the regulation of the stress response. Activation of AVP and OXT receptors oppositely affects fear and anxiety-related behaviors (Huber, Veinante \& Stoop, 2005). AVP has been shown to enhance stress levels whereas OXT has been shown to decrease anxiety and stress (Landgraf \& Neumann, 2004). Cortisol, which is one of the primary stress hormones activating the body during a stress reaction, is regulated by the HPA-axis and thus influenced by OXT and AVP. Twin studies have shown that vocal symptoms are influenced by genes (Nybacka et al. 2012; Simberg et al., 2009). As oxytocin and vasopressin regulate the stress response and stress is an important risk factor for vocal symptoms, we hypothesized that $O X T R$ and AVPR1A polymorphism may influence the occurrence of vocal symptoms. We also hypothesized that the effect of $O X T R$ and $A V P R 1 A$ on vocal symptoms might be mediated by cortisol.

The vocal symptoms occurred weekly or more often in $8.2-27.1 \%$ of the participants. The occurrence of vocal symptoms in our dataset is comparable with earlier studies (Lyberg Åhlander, Rydell, Fredlund, Magnusson, Wilén, 2015; Roy, Merrill, Gray \& Smith, 2005).

A main effect was found regarding three OXTR polymorphisms (rs2270465, rs2268493, rs7632287) when $\alpha=0.05$. These SNPs did not remain significant, however, after controlling for multiple tests, so the results should be interpreted with caution. 
None of these SNPs have yet been studied in relation to stress reactivity. However, all three polymorphisms have in previous studies been associated with social behavior (Westberg \& Walum, 2015). Both rs2270465 (Wermter, Kamp-Becker, Hesse, SchulteKorne, Strauch \& Remschmidt, 2010), rs2268493 (Campbell et al., 2011) and rs7632287 (Campbell et al., 2011; Tansey et al., 2010) have been associated with risk for autism spectrum disorder. The rs7632287 has also been associated with pair-bonding (Walum et al., 2012). No study has previously shown associations between the polymorphism rs2268493 and stress and/or cortisol levels. In a study by Kawamura et al. (2010) investigating affective temperaments, the results showed an association between depressive temperament and a specific OXTR haplotype (set of alleles on one chromosome), where the rs2268493 was as one of the seven polymorphisms in the haplotype.

The results showed that the effect of the OXTR rs2268493 on vocal symptoms might be mediated by cortisol. This indirect effect could possibly be due to the fact that OXT might buffer the stress reactivity associated with a reduction of cortisol secretion (Cardoso et al., 2014; de Jong et al. 2015). An alternative or complementary pathway of the cortisol mediation is that OXT and AVP influence anxiety and stress through pathways within the brain. OXT and AVP travel along axons from the hypothalamus to for example the amygdala, where they modulate the activity of the amygdala (Bethlehem et al., 2013; Huber et al., 2005; Meyer-Lindenberg et al. 2011). The amygdala plays a key role in the neuroendocrine and autonomic responses to stress (Ulrich-Lai \& Herman, 2009), fear (Davis, 1992) and emotion regulation (Lee, Macbeth, Pagani \& Young $3^{\text {rd }}$, 2009). OXT attenuates amygdala reactivity (Labuschagne et al. 2010), whereas AVP promotes increased amygdala activation (Herman \& Cullinan, 1997; Herman, Ostrander, Mueller \& Figueiredo, 2005). Intriguingly in this context is that Damiano et al. (2014) found that the rs2268493 moderates mesolimbic responses during reward anticipation, which involves areas like the amygdala and the thalamus. However, these results should be interpreted with caution, since the specific association between OXTR and OXT-levels in the brain and in the body, as well as the association of OXT and glucocorticoid reactivity during stress, is not yet fully understood. 
Since the functionality of the tested SNPs is still unclear, it is difficult at this point to know exactly how the SNPs would affect cortisol levels. However, two potential paths could be hypothesized that could act separately or in combination (as is more likely): a) the SNPs could through their effects on oxytocin function physiologically affect cortisol levels, or b) the SNPs could through their effects on social traits, influence for example, seeking of peer support during stress, which in turn could alleviate stress symptoms and lower cortisol levels.

OXTR SNP rs53576 has previously been associated with empathy and stress reactivity (Rodrigues et al., 2009), interaction with stress-protective effects such as social support (Chen et al., 2011) and responses to acute stressors (Moons et al., 2014). In the present dataset the rs53576 did not show any effect on vocal symptoms.

Two AVPR1A polymorphisms (rs1587097, rs1042615) showed main effects on vocal symptoms when $\alpha=0.05$. The effect of the $A V P R 1 A$ polymorphism rs1587097 on vocal symptoms remained significant after the $\alpha$-level was corrected to account for multiple testing, whereas the rs1042615 did not. Studies regarding these specific SNP have not so far been analyzed in association to stress. Levran et al. (2014) studied the relationship between gene variations in stress-related genes and substance abuse. The polymorphism rs1587097 was identified as one of the polymorphisms that showed a nominally significant association with heroin addiction, cytosine $(\mathrm{C})$ being the risk allele, which was also the case in the current study. The $A V P R 1 A$ RS1 has previously been associated with circulating levels AVP and emotional responses to an acute stressor (Moons et al., 2014). However, this polymorphism was not included in the present dataset.

Recently, instead of analyzing the effects of SNPs individually, gene-based tests have become increasingly common. The rationale behind gene-based tests is that the gene is the functional unit of the genome, and by analyzing the SNPs of a gene jointly, increases in statistical power can be gained. Furthermore, gene-based tests have been argued to be biologically more relevant unit of analysis than SNPs (Neale \& Sham, 2004). Although 
multiple nominal associations were seen between SNPs in both the OXTR and the AVPR $1 A$ genes on vocal symptoms, the gene-based tests using VEGAS did not reach significance, although there was suggestive evidence of associations before controlling for multiple tests. It is possible that these are true negative finding; however, including more SNPs per gene could have given more coverage of the gene and higher statistical power to identify possible effects, thus giving more confidence in the results. A recent paper used a latent variable model to analyze the joint effects of SNPs in the OXTR gene (LoParo et al., 2015), which could be an interesting approach for future analyzes since using latent variables further increases statistical power (Wang, Jacob, Ghosh, Wang \& Zeng, 2009). Another important way to increase the statistical power in future studies is of course by increasing the sample sizes, either in independent studies or by using metaanalyses to combine results from several studies.

We should note some limitations of the current study as well as issues that could be assessed in future research. Retrospective self-reports of vocal symptoms were used, which could be influenced by recall bias. Using saliva samples is a noninvasive method suitable for studying a larger group of participants. However, using a mean level of multiple cortisol samples over several days, instead of one, would have provided us with more reliable results. Also the number of participants that submitted saliva samples for hormone analysis $(n=170)$ was notably smaller than the number of participants who provided saliva samples for genotyping $(n=657)$. The differences in group size might have influenced the statistical power of the analysis. Secondly, it may be that the tested polymorphisms are irrelevant to the observed association, and that neighboring SNPs in linkage disequilibrium are the functional ones. The function of these SNPs is still unclear as well as their relation to the levels of oxytocin and vasopressin in the brain and blood stream. It is, however, possible that they could have an influence on gene function as indicated by in silico analyses. The rs2268493 OXTR SNP showing nominal effects on vocal symptoms, through possible cortisol mediation, is located in an intron and together with other SNPs in linkage disequilibrium with it (LD; r2 >.60), appears to alter binding motifs for 14 transcription factors (HaploReg; Ward \& Kellis, 2011). The effects of the AVPR1A 3' UTR SNP rs1587097 on vocal symptoms remained significant after 
controlling for multiple tests. This SNP, together with other SNPs in LD >.60 with it, in turn, appears to alter 8 transcription factors (HaploReg; Ward \& Kellis, 2011).

Estimations of the effect sizes should only be seen as approximations. In addition, even though the effect size estimates for nominally significant effects were moderate in magnitude (Cohen's $d$ ranging between 0.23-0.41), these are likely overestimations of true effect sizes, as is usually the case in candidate-gene association analyses, since genome-wide association analyses have indicated that single SNPs affecting complex human behaviors often explain less than $1 \%$ of the phenotypic variance (Visscher, Brown, McCarthy \& Yang, 2012). Despite small effects of single SNPs, identification of novel variants can lead to biological insights of relevance to the trait. Research regarding additional stress related SNPs and replication of this study is needed to identify the specific pathways in which OXT and AVP influence vocal symptoms. We found nominal as well as significant main effects regarding some $O X T R$ and $A V P R 1 A$ and vocal symptoms. Since other factors, such as means of social support (OXT) and aggressive behavior (AVP), also might influence the relationship between OXT, AVP, stress and cortisol, it would be advisable to include these factors in future research. Possible gender differences could also be further explored, since there is evidence that $O X T R$ and AVPR1A could predict gender specific emotional responses to acute stressors (Moons et al., 2014). Next step will also be to further explore clinical implications. This type of research would increase our understanding of how the oxytocin and vasopressin system affects the stress response and risk for vocal symptoms.

\section{References}

Aguilera, G. \& Rabadan-Diehl, C.R. (2000). Vasopressinergic regulation of the hypothalamic-pituitary-adrenal axis: implications for stress adaptation. Regulatory Peptides, 96, 23-29.

Apicella, C.L., Cesarini, D., Johannesson, M., Dawes, C.T., Lichtenstein, P., Wallace, B., Beauchamp, J., \& Westberg, L. (2010). PLoS One, 5, e11153.

Auer, B.J., Byrd-Craven, J., Grant, D.M., \& Granger, D.A. (2015). Common oxytocin receptor gene variant interacts with rejection sensitivity to influence cortisol reactivity during negative evaluation. Hormones and Behavior, 75, 64-69.

doi: 10.1016/j.yhbeh.2015.07.023. 
Axelrod, J. \& Reisine, T.D. (1984). Stress hormones: their interaction and regulation. Science, 224, 452-459.

Baker, J. (2008). The role of psychogenic and psychosocial factors in the development of functional voice disorders. International Journal of Speech-Language Pathology, 10, 210-230. doi:10.1080/17549500701879661

Bakermans-Kranenburg, M.J. \& van Ijzendoorn, M.H. (2008). Oxytocin receptor (OXTR) and serotonin transporter (5-HTT) genes associated with observed parenting. Social Cognitive and Affective Neuroscience, 3, 128-134.

Bethlehem, R.A.I., van Honk, J., Auyeung, B., Baron-Cohen, S.,2013. Oxytocin, brain physiology, and functional connectivity:a review of intranasal oxytocin fMRI studies. Psychoneuroen-docrinology, 38, 962-974.

Campbell, D.B., Datta, D., Jones, S.T., Batey Lee, E., Sutcliffe, J.S., Hammock, E.A., \& Levitt, P. (2011). Association of oxytocin receptor (OXTR) gene variants with multiple phenotype domains of autism spectrum disorder. Journal of Neurodevelopmental Disorders, 3, 101-112. doi: 10.1007/s11689-010-9071-2.

Cardoso, C., Kingdon, D., Ellenbogen, M.A. (2014). A meta-analytic review of the impact of intranasal oxytocin administration on cortisol concentrations during laboratory tasks: moderation by method and mental health. Psychoneuroendocrinology, $49,161-170$.

Chen, S.H., Chiang, S.C., Chung, Y.M., Hsiao, L.C., \& Hsiao, T.Y. (2010). Risk factors and effects of voice problems for teachers. Journal of Voice, 24, 183-192. doi:10.1016/j.jvoice.2008.07.008.

Chen, F.S., Kumsta, R., von Dawans, B., Monakhov, M., Ebstein, R.P., \& Heinrichs, M. (2011). Common oxytocin receptor gene $(O X T R)$ polymorphism and social support interact to reduce stress in humans. Proceedings of the National Academy of Sciences, 108, 19937-19942.

Cohen, J. (1992). A power primer. Psychological Bulletin, 112 (1), 155-159.

Davis, M. (1992). The role of the amygdala in fear and anxiety. Annual Review of Neuroscience, 15, 353-375. doi: 10.1146/annurev.ne.15.030192.002033

Damiano, C.R., Aloi, J., Dunlap, K., Burrus, C.J., Mosner, M.G., Kozink, R.V., ... Dichter G.S. (2014). Association between the oxytocin receptor (OXTR) gene and mesolimbic responses to rewards. Molecular Autism, 5, 1-12. doi: 10.1186/2040-2392-5-7. 
Dietrich, M., \& Verdolini Abbott, K. (2012). Vocal function in introverts and extraverts during a psychological stress reactivity protocol. Journal of Speech, Language and Hearing Research, 55, 973-987.

Dietrich, M., Verdolini Abbott, K., Gartner-Schmidt, J., \& Rosen, C.L. (2008). The frequency of perceived stress, anxiety and depression in patients with common pathologies affecting voice. Journal of Voice, 22, 472-488.

Di Napoli, A., Warrier, V., Baron-Cohen, S., \& Chakrabarti, B. (2014). Genetic variation in the oxytocin receptor (OXTR) gene is associated with Asperger Syndrome. Molecular Autism, 5, 48.

Ditzen, B., Schaer, M., Gabriel, B., Bodenmann, G., Ehlert, U., \& Heinrichs, M. (2009). Intranasal oxytocin increases positive communication and reduces cortisol levels during couple conflict. Biological Psychiatry, 65, 728-731.

Enhörning, S., Leosdottir, M., Wallström, P., Gullberg, B., Berglund, G., Wirfält, E., \& Melander O. (2009). Relation between human vasopressin 1a gene variance, fat intake, and diabetes. The American Journal of Clinical Nutrition, 89, 400-406.

Feldman, R., Zagoory-Sharon, O., Weisman, O., Schneiderman, I., Gordon, I., Maoz, R., Shalev, I., \& Ebstein, R.P. (2012) Sensitive parenting is associated with plasma oxytocin and polymorphisms in the OXTR and CD38 genes. Biological Psychiatry, 72, 175-181. doi: 10.1016/j.biopsych.2011.12.025.

Gardiner, J.S., Luo, Z., \& Roman, L.A. (2009). Fixed effects, random effects and GEE: What are the differences? Statistics in Medicine, 28, 221-239.

Gassull, C., Casanova, C., Botey, Q., \& Amador, M. (2010). The impact of the reactivity to stress in teachers with voice problems. Folia Phoniatrica et Logopedica, 62, 35-39.

Giddens, C.L., Barron, K.W., Byrd-Craven, J., Clark, K.F., \& Winter, A.S. (2013). Vocal indices of stress: a review. Journal of Voice, 27, e21-29.

Grewen, K.M., \& Light, K.C. (2011). Plasma oxytocin is related to lower cardiovascular and sympathetic reactivity to stress. Biological Psychology, 87, 340-349.

Hanley, J.A., Negassa, Abdissa, Edwardes, M.D. de B., \& Forrester, J.E. (2003). Statistical analysis of correlated data using Generalized Estimating Equations: An orientation. American Journal of Epidemiology, 157, 364-375.

Heinrichs, M., Baumgartner, T., Kirschbaum, C., \& Ehlert, U. (2003). Social support and oxytocin interact to suppress cortisol and subjective responses to psychosocial stress.

Biological Psychiatry, 54, 1389-1398. 
Hellhammer, D.H., Wüst, S., \& Kudielka, B.M. (2009). Salivary cortisol as a biomarker in stress research. Psychoneuroendocrinology, 34, 163-171

doi: 10.1016/j.psyneuen.2008.10.026

Herman, J.P., Ostrander, M.M., Mueller, N.K., \& Figueiredo, H. (2005). Limbic system mechanisms of stress regulation: hypothalamo-pituitary-adrenocortical axis. Progress in Neuro-psychopharmacology \& Biological Psychiatry, 29, 1201-1213.

Herman, J.P. \& Cullinan, W.E. (1997). Neurocircuitry of stress: central control of the hypothalamo-pituitary-adrenocortical axis. Trends in Neuroscience, 20, 78-84.

Holmqvist, S., Johansson, A., Santtila, P., Westberg' L., von der Pahlen, B., \& Simberg, S. (submitted). Investigating the role of salivary cortisol on vocal symptoms. Journal of Speech, Language, and Hearing Research.

Huber, D., Veinante, P., \& Stoop, R. (2005). Vasopressin and oxytocin excite distinct neuronal populations in the central amygdala. Science, 308, 245-248.

Inoue, H., Yamasue, H., Tochigi, M., Abe, O., Liu, X., Kawamura, Y., ...\& Kasai, K. (2010). Association between the oxytocin receptor gene and amygdalar volume in healthy adults. Biological Psychiatry, 68, 1066-1072. doi: 10.1016/j.biopsych.2010.07.019.

Insel, T.R. (2010). The challenge of translation in social neuroscience: a review of oxytocin, vasopressin, and affiliative behavior. Neuron, 65, 768-779.

Israel, S., Lerer, E.. Shalev, I., Uzefovsky, F., Riebold, M., Laiba, E., ... \& Ebstein, R.P. (2009). The oxytocin receptor (OXTR) contributes to prosocial fund allocations in the dictator game and the social value orientations task. PLoS One, 4, e5535. doi: 10.1371/journal.pone.0005535.

Jacob, S., Brune, C.W., Carter, C.S., Leventhal, B.L., Lord, C., \& Cook, E.H. Jr. (2007). Association of the oxytocin receptor gene (OXTR) in Caucasian children and adolescents with autism. Neuroscience Letters, 417, 6-9.

Jern, P., Westberg, L., Johansson, A., Jonsson, L., Corander, J., Sandnabba, N.K., \& Santtila, P. (2012). Are single nucleotide polymorphisms in the oxytocin and vasopressin $1 \mathrm{~A} / 1 \mathrm{~B}$ receptor genes likely candidates for variation in ejaculatory function? British Journal of Urology International, 110, E1173-1180.

Jezová, D,, Juránková, E., Mosnárová, A., Kriska, M., \& Skultétyová, I. (1996). Neuroendocrine response during stress with relation to gender differences. Acta neurobiologiae experimentalis, 56, 779-785.

Johansson, A., Bergman, H., Corander, J., Waldman, I.D., Karrani, N., Salo, B., Jern, P., Algars, M., Sandnabba, K., Santtila, P., \& Westberg, L. (2012a). Alcohol and aggressive 
behavior in men - moderating effects of oxytocin receptor gene (OXTR) polymorphisms. Genes, Brain and Behavior, 11, 214-221. doi: 10.1111/j.1601-183X.2011.00744.x

Johansson, A., Westberg, L., Sandnabba, K., Jern, P., Salo, B., \& Santtila, P. (2012b). Associations between oxytocin receptor gene $(O X T R)$ polymorphisms and self-reported aggressive behavior and anger: Interactions with alcohol consumption.

Psychoneuroendocrinology, 37, 1546-1556. doi: 10.1016/j.psyneuen.2012.02.009.

Johansson, A., Jern, P., Santtila, P., von der Pahlen, B., Eriksson, E., Westberg, L., Nyman, H., Pensar, J., Corander, J., \& Sandnabba, N.K. (2013). The genetics of sexuality and aggression (GSA) twin samples in Finland. Twin Research and Human Genetics, 16, $150-156$.

de Jong, T.R., Menon, R., Bludau, A., Grund, T., Biermeier, V., Klampfl, S.M., ... Neumann, I.D. (2015). Salivary oxytocin concentrations in response to running, sexual self-stimulation, breastfeeding and the TSST: The Regensburg Oxytocin Challenge (ROC) study. Psychoneuroendocrinology, 62, 381-388.

doi: 10.1016/j.psyneuen.2015.08.027.

Kawamura, Y., Liu, X., Akiyama, T., Shimada, T., Otowa, T., Sakai, Y., Kakiuchi, C., Umekage, T., Sasaki, T., \& Akiskal, H.S. (2010). The association between oxytocin receptor gene $(O X T R)$ polymorphisms and affective temperaments, as measured by TEMPS-A. Journal of Affective Disorders, 127, 31-37.

Kenny, D.A., \& Judd, C.M. (2014).Power Anomalies in Testing Mediation. Psychological Science, 25, 334-339.

de Kloet, E.R., Joëls, M., \& Holsboer, F. (2005) Stress and the brain: from adaptation to disease. Nature Reviews Neuroscience, 6, 463-475.

Labuschagne, I., Phan, K.L., Wood, A., Angstadt, M., Chua, P., Heinrichs, M., Stout, J.C., Nathan, P.J. (2010). Oxytocin attenuates amygdala reactivity to fear in generalized social anxiety disorder. Neuropsychopharmacology, 35, 2403-2413.

doi: $10.1038 / \mathrm{npp} .2010 .123$.

Landgraf, R., \& Neumann, I.D. (2004). Vasopressin and oxytocin release within the brain: a dynamic concept of multiple and variable modes of neuropeptide communication. Frontiers in Neuroendocrinology, 25, 150-176.

Lee, H-J., Macbeth, A.H., Pagani, J., \& Young, W. S. $3^{\text {rd }}$ (2009). Oxytocin: the great facilitator of life. Progress in Neurobiology, 88, 127-151.

Legros, J.J. (2001). Inhibitory effect of oxytocin on corticotropefunction in humans: are vasopressin and oxytocin ying-yang neu-rohormones? Psychoneuroendocrinology, 26, 649-655. 
Lerer, E., Levi, S., Salomon, S., Darvasi, A., Yirmiya, N., \& Ebstein, R.P. (2008). Association between the oxytocin receptor $(O X T R)$ gene and autism: relationship to Vineland Adaptive Behavior Scales and cognition. Molecular Psychiatry, 13, 980-988.

Levran, O., Peles, E., Randesi, M., Li, Y., Rotrosen, J., Ott, J., Adelson, M., \& Kreek, M.J. (2014). Stress-related genes and heroin addiction: a role for a functional FKBP5 haplotype. Psychoneuroendocrinology, 45, 67-76.

Li, J. \& Ji, L. (2005). Adjusting multiple testing in multilocus analyses using the eigenvalues of a correlation matrix. Heredity, 95, 221-227.

Liu, J.Z., McRae, A.F., Nyholt, D.R., Medland, S.E., Wray, N.R., Brown, ... \& Macgregor, S. (2010). A versatile gene-based test for genome-wide association studies. The American Journal of Human Genetics, 87, 139-145.

doi: 10.1016/j.ajhg.2010.06.009

LoParo, D., Johansson, A., Walum, H., Westberg, L., Santtila, P., \& Waldman, I. (2015). Rigorous tests of gene-environment interactions in a lab study of the oxytocin receptor gene (OXTR), alcohol exposure, and aggression. American Journal of Medical Genetics Part B: Neuropsychiatric Genetics 9999, 1-14. doi: 10.1002/ajmg.b.32359.

LoParo, D. \& Waldman, I.D. (2014). The oxytocin receptor gene (OXTR) is associated with autism spectrum disorder: a meta-analysis. Molecular Psychiatry, 20, 640-646. doi: $10.1038 / \mathrm{mp} .2014 .77$.

Lyberg Åhlander, V., Rydell, R., Fredlund, P., Magnusson, C., Wilén S. (2015).

Prevalence of voice disorders in the general population in Sweden. Abstract presented at Pan European Voice Conference PEVOC11, September 2015.

Maher, B.S., Vladimirov, V.I., Latendresse, S.J., Thiselton, D.L., McNamee, R., Kang, ... \& Vanyukov, M.M. (2011). The AVPR1A gene and substance use disorders: Association, replication, and functional evidence. Biological Psychiatry, 70, 519-527. doi: 10.1016/j.biopsych.2011.02.023.

Malik, A.I., Zai, C.C., Abu, Z., Nowrouzi, B., \& Beitchman, J.H. (2012). The role of oxytocin and oxytocin receptor gene variants in childhood-onset aggression. Genes, Brain and Behavior, 11, 545-551.

Meyer-Lindenberg, A., Kolachana, B., Gold, B., Olsh, A., Nicodemus, K.K., Mattay, V., Dean, M., \& Weinberger, D.R. (2009). Genetic variants in AVPRIA linked to autism predict amygdala activation and personality traits in healthy humans. Molecular Psychiatry , 14, 968-975.

Meyer-Lindenberg, A., Domes, G., Kirsch, P., \& Heinrichs, M. (2011). Oxytocin and vasopressin in the human brain: social neuropeptides for translational medicine. Nature Reviews Neuroscience, 12, 524-538. 
Myers, A.J., Williams, L., Gatt, J.M., McAuley-Clark, E.Z., Dobson-Stone, C., Schofield, P.R., \& Nemeroff, C.B. (2014). Variation in the oxytocin receptor gene is associated with increased risk for anxiety, stress and depression in individuals with a history of exposure to early life stress. Journal of Psychiatric Research, 59, 93-100.

doi: 10.1016/j.jpsychires.2014.08.021.

Moons, W.G., Way, B.M., \& Taylor S.E. (2014). Oxytocin and vasopressin receptor polymorphisms interact with circulating neuropeptides to predict human emotional reactions to stress. Emotion, 14, 562-572.

Neale, B.M. \& Sham, P.C. (2004). The future of association studies: gene-based analysis and replication. American Journal of Human Genetics, 75, 353-362.

Neumann, I.D., \& Landgraf, R. (2012). Balance of brain oxytocin and vasopressin: implications for anxiety, depression, and social behaviors.

Neumann, I.D., Wigger, A., Torner, L., Holsboer, F., \& Landgraf, R.(2000). Brain oxytocin inhibits basal and stress-induced activity of the hypothalamo-pituitary-adrenal axis in male and female rats: partial action within the paraventricular nucleus. Journal of Neuroendocrinology, 12, 235-243.

Nybacka, I., Simberg, S., Santtila, S., Sala, E., \& Sandnabba, NK. (2012). Genetic and environmental effects on vocal symptoms and their intercorrelations. Journal of Speech, Language, and Hearing Research, 55, 541-553.

Nyholt, D.R. (2004). A simple correction for multiple testing for single-nucleotide polymorphisms in linkage disequilibrium with each other. American Journal of Human Genetics, 74, 765-769.

Olff, M., Frijling, J.L., Kubzansky, L.D., Bradley, B., Ellenbogen, M.A., Cardoso, C., Bartz, J.A., ..., \& van Zuiden, M. (2013). The role of oxytocin in social bonding, stress regulation and mental health: an update on the moderating effects of context and interindividual differences. Psychoneuroendocrinology, 38, 1883-1894. doi: 10.1016/j.psyneuen.2013.06.019. Epub 2013 Jul 12.

Rantala, L.M., Hakala, S.J. Holmqvist, S., \& Sala E. (2012). Connections between voice ergonomic risk factors and voice symptoms, voice handicap, and respiratory tract diseases. Journal of Voice, 26, 819.e13-819.e20.

Rodrigues, S.M., Saslow, L.R., Garcia, N., John, O.P., \& Keltner D. (2009). Oxytocin receptor genetic variation relates to empathy and stress reactivity in humans. Proceedings of the National Academy of Sciences of the United States of America, 106, 21437-21441.

Rosell, D.R. \& Siever, L.J. (2015). The neurobiology of aggression and violence. CNS Spectrums, 20, 254-279. doi: 10.1017/S109285291500019X 
Roy, N., Merrill, R.M., Gray, S.D., \& Smith, E.M. (2005). Voice disorders in the general population: prevalence, risk factors, and occupational impact. The Laryngoscope, 115, 1988-1995.

Sala, E., Laine, A., Simberg, S., Pentti, J., \& Suonpää, J., (2001). The prevalence of voice disorders among day care center teachers compared with nurses: a questionnaire and clinical study. Journal of Voice. 15, 413-423.

Seifert, E., \& Kollbrunner, J. (2005). Stress and distress in non-organic voice disorders. Swiss Medical Weekly, 135, 387-397.

Seltzer, L. J., Ziegler, T. E., \& Pollak, S. D. (2010). Social vocalizations can release oxytocin in humans. Proceedings of the Royal Society B: Biological Sciences, 277, 26612666. http://doi.org/10.1098/rspb.2010.0567

Shalev, I., Israel, S., Uzefovsky, F., Gritsenko, I., Kaitz, M., \& Ebstein, R.P. (2011). Vasopressin needs an audience: neuropeptide elicited stress responses are contingent upon perceived social evaluative threats. Hormones and Behavior, 60, 121-127.

Simberg, S., Sala, E., Tuomainen, J., Sellman, J., \& Rönnemaa, A-M. (2006). The effectiveness of group therapy for students with mild voice disorders: A controlled clinical trial. Journal of Voice, 20, 97-109.

Simberg, S., Santtila, P., Soveri, A., Varjonen, M., Sala, E., \& Sandnabba, K. (2009). Exploring genetic and environmental effects in dysphonia: A twin study. Journal of Speech, Language, and Hearing Research, 52, 153-163.

Skuse, D.H., Lori, A., Cubells, J.F., Lee, I., Conneely, K.N., Puuram K., ... \& Young, L.J. (2014). Common polymorphism in the oxytocin receptor gene (OXTR) is associated with human social recognition skills. Proceedings of the National Academy of Sciences of the United States of America, 111, 1987-1992.

Tansey, K.E., Brookes, K.J., Hill, M.J., Cochrane, L.E., Gill, M., Skuse, D., .. \& \& Anney, R.J.L. (2010). Oxytocin receptor (OXTR) does not play a major role in the aetiology of autism: genetic and molecular studies. Neuroscience Letters, 474, 163-167.

Thompson, R. J., Parker, K. J., Hallmayer, J. F., Waugh, C. E., \& Gotlib, I. H. (2011). Oxytocin receptor gene polymorphism (rs2254298) interacts with familial risk for psychopathology to predict symptoms of depression and anxiety in adolescent girls. Psychoneuroendocrinology, 36, 144-147.

Tops, M., van Peer, J.M., \& Korf, J. (2007). Individual differences in emotional expressivity predict oxytocin responses to cortisol administration: relevance to breast cancer? Biological Psychology, 75, 119-123. 
Tost, H., Kolachana, B., Hakimi, S., Lemaitre, H., Verchinski, B.A., Mattay, V.S. ..., \& Meyer-Lindenberg, A. (2010). A common allele in the oxytocin receptor gene (OXTR) impacts prosocial temperament and human hypothalamic-limbic structure and function. Proceedings of the National Academy of Sciences of the United States of America, 107, 13936-13941.

Ulrich-Lai, Y.M. \& Herman, J.P. (2009). Neural regulation of endocrine and autonomic stress responses. Nature Reviews Neuroscience, 10, 397-409. doi:10.1038/nrn2647

Vining, R.F., \& McGinley, R.A. (1987). The measurement of hormones in saliva: Possibilities and pitfalls. Journal of Steroid Biochemistry, 27, 81-94.

Visscher, P.M., Brown, M.A., McCarthy, M.I., \& Yang, J. (2012). Five years of gwas discovery. American Journal of Human Genetics, 90, 7-24.

Walum, H., Lichtenstein, P., Neiderhiser, M., Reiss, D., Ganiban, J.M., Spotts, E.L., ... Westberg, L. (2012). Variations in the oxytocin receptor gene is associated with pairbonding and social behavior. Biological Psychiatry, 71, 419-426.

Walum, H. Westberg, L., Henningsson, S., Neiderhiser, J.M., Reiss, D., Igl, W., ... Lichtenstein, P. (2008). Genetic variation in the vasopressin receptor 1a gene (AVPR1A) associates with pair-bonding behavior in humans. Proceedings of the National Academy of Sciences of the United States of America, 105, 14153-14156.

Wang, T., Jacob, H., Ghosh, S., Wang, X., \& Zeng, Z.B. (2009). A joint association test for multiple SNPs in genetic case-control studies. Genetic Epidemiology, 33, 151-163. doi: $10.1002 /$ gepi.20368.

Wang, K., Zhang, H., Ma, D., Bucan, M., Glessner, J.T., Abrahams, B.S. ... \& Hakonarson, H. (2009) Common genetic variants on 5p14.1 associate with autism spectrum disorders. Nature; 459, 528-533.

Walter, N.T., Montag, C., Markett, S., Felten, A., Voigt, G., Reuter, M. (2012). Ignorance is no excuse: moral judgments are influenced by a genetic variation on the oxytocin receptor gene. Brain and Cognition, 78, 268-73. doi: 10.1016/j.bandc.2012.01.003.

Ward, L.D. \& Kellis, M. (2011). HaploReg: a resource for exploring chromatin states, conservation, and regulatory motif alterations within sets of genetically linked variants. Nucleic Acids Research, 1-5.

Wermter, A. K., Kamp-Becker, I., Hesse, P., Schulte-Korne, G., Strauch, K., \& Remschmidt, H. (2010). Evidence for the involvement of genetic variation in the oxytocin receptor gene $(O X T R)$ in the etiology of autistic disorders on high-functioning level. American Journal of Medical Genetics Part B: Neuropsychiatric Genetics, 153B, 629-639. 
Westberg, L. \& Walum H. (2015). Oxytocin and vasopressin gene variation and the neural basis of social behaviors in Oxford Handbooks Online. Retrieved 14 Jan. 2015, from http://www.oxfordhandbooks.com/view/10.1093/oxfordhb/9780199753888.001.000 1/oxfordhb-9780199753888-e-011. doi:10.1093/oxfordhb/9780199753888.001.0001.

Wittig, R. M., Crockford, C., Deschner, T., Langergraber, K. E., Ziegler, T. E., \& Zuberbühler, K. (2014). Food sharing is linked to urinary oxytocin levels and bonding in related and unrelated wild chimpanzees. Proceedings of the Royal Society B: Biological Sciences, 281, 20133096. http://doi.org/10.1098/rspb.2013.3096

Wu, N., Li, Z., \& Su, Y. (2012). The association between oxytocin receptor gene polymorphism (OXTR) and trait empathy. Journal of Affective Disorders, 138, 468-472.

Yang, S.Y., Cho, S.C., Cho, I.H., Park, M., Kim, B.N., Kim, J.W. ... \& Kim, S.A. (2010). Association study between single-nucleotide polymorphisms in promoter region of AVPR1A and Korean autism spectrum disorders. Neuroscience Letters, 479, 197-200.

Zietsch, B.P., Westberg, L., Santtila, P., \& Jern, P. (2015). Genetic analysis of human extrapair mating: heritability, between-sex correlation, and receptor genes for vasopressin and oxytocin. Evolution and Human Behavior, 36, 130-136. 